\title{
Excited-State Proton Transfer in Gas-Expanded Liquids: The Roles of Pressure and Composition in Supercritical $\mathrm{CO}_{2} /$ Methanol Mixtures
}

\author{
Rui M. D. Nunes, ${ }^{\dagger}$ Luis G. Arnaut, ${ }^{, \dagger}{ }^{\dagger}$ Kyril M. Solntsev, ${ }^{*}, \ddagger$ Laren M. Tolbert, ${ }^{*, \neq}$ and \\ Sebastião J. Formosinho ${ }^{\dagger}$ \\ Department of Chemistry, University of Coimbra, 3000 Coimbra, Portugal, and School of Chemistry and \\ Biochemistry, Georgia Institute of Technology, Atlanta, Georgia 30332-0400
}

Received April 14, 2005; E-mail: Igarnaut@ci.uc.pt; solntsev@chemistry.gatech.edu; tolbert@chemistry.gatech.edu

Molecules that increase their acidity constant upon electronic excitation $\left(\mathrm{p} K_{\mathrm{a}} *<\mathrm{p} K_{\mathrm{a}}\right)$ have been known for half a century ${ }^{1}$ and have contributed significantly to our understanding of proton transfer in aqueous solutions. ${ }^{2}$ Recent advances in this area have focused on excited-state proton transfer (ESPT) in organic media, making use of a new generation of photoacids $\left(\mathrm{p} K_{\mathrm{a}} *<0\right)^{3}$ such as the remarkable "super" photoacid, 5,8-dicyano-2-naphthol (DCN2). Unlike the parent 2-naphthol, DCN2 combines a remarkably strong acidity $\left(\mathrm{p} K_{\mathrm{a}}{ }^{*}=-4.5\right.$ in aqueous solution) with very fast proton transfer to organic solvents and very intense fluorescence for both nondissociated $\left(\mathrm{R}^{*} \mathrm{OH}\right)$ and anionic $\left(\mathrm{R}^{*} \mathrm{O}^{-}\right)$forms. ${ }^{4}$ Such super photoacids raise the possibility of inducing proton jumps in cosolvent-modified supercritical fluids or in gas-expanded liquids. In view of the growing importance of supercritical carbon dioxide $\left(\mathrm{scCO}_{2}\right)$ as a processing solvent and as a reaction medium, particularly for reactions involving proton transfer, and of the interest in adding cosolvents to tailor the properties of $\mathrm{scCO}_{2}$, we now report the proton-transfer properties of DCN2 in $\mathrm{MeOH} / \mathrm{CO}_{2}$ mixtures, using methanol mole fractions $\left(X_{\mathrm{MeOH}}\right)$ ranging from 0.2 to 0.7 . ESPT in $\mathrm{MeOH} / \mathrm{CO}_{2}$ mixtures has been attempted using 2-naphthol and 5-cyano-2-naphthol (5CN2), but the authors failed to detect any naphtholate emission. ${ }^{5}$ The success of the present work is tied to the much higher acidity of DCN2.

Absorption, fluorescence, and single-photon counting measurements of DCN2 in $\mathrm{MeOH} / \mathrm{CO}_{2}$ mixtures at temperatures between 307 and $330 \mathrm{~K}$ and pressures between 9.5 and $25 \mathrm{MPa}$ followed standard procedures. ${ }^{6,7}$ Mole fractions $X_{\mathrm{MeOH}}$ at $323 \mathrm{~K}$ were calculated from the $\mathrm{MeOH}$ volume in the cell at room temperature and the density of $\mathrm{MeOH} / \mathrm{CO}_{2}$ mixtures at this temperature. ${ }^{8}$ Visual inspection ensured that a single phase was present in all the experiments. The pressures and temperatures in this study were in the supercritical region of $\mathrm{CO}_{2}$.

DCN2 in $\mathrm{scCO}_{2}$ has only one fluorescence band, with a maximum at $395 \mathrm{~nm}$, assigned to $\mathrm{R} * \mathrm{OH}$. With the addition of $\mathrm{MeOH}$ the $\mathrm{R} * \mathrm{OH}$ emission maximum first shifts to $440 \mathrm{~nm}$, and at a minimum concentration of $\mathrm{MeOH}$, a new emission, assigned to $\mathrm{R}^{*} \mathrm{O}^{-}$, was observed at $580 \mathrm{~nm}$, Figure 1 . The positions of these maxima were virtually the same for all the $\mathrm{MeOH} / \mathrm{CO}_{2}$ mixtures measured in this work. In pure methanol, these two bands were observed at 440 and $600 \mathrm{~nm}$, respectively. The frequencies of the $\mathrm{R} * \mathrm{OH}$ emission maxima of naphthols were correlated with the polarizability $\left(\pi^{*}\right)$ and the hydrogen-bond accepting/electron-pair donating $(\beta)$ parameters of Taft. ${ }^{9}$ The $2590 \mathrm{~cm}^{-1}$ shift observed from methanol to $\mathrm{scCO}_{2}$ was larger than the $2350 \mathrm{~cm}^{-1}$ shift reported for $5 \mathrm{CN} 2$ when the solvent was changed from methanol to hexane. The very low polarizability of $\mathrm{scCO}_{2}\left(\pi^{*}\right.$ values between -0.1 and -0.4 in the $9.5-25 \mathrm{MPa}$ pressure range $)^{10 a}$ favors such

\footnotetext{
$\dagger$ University of Coimbra.

\# Georgia Institute of Technology.
}

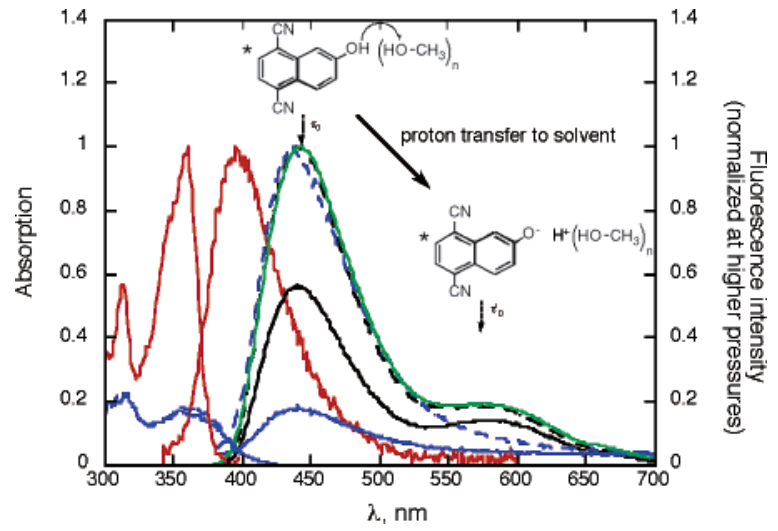

Figure 1. Fluorescence excitation and emission of $\mathrm{DCN} 2$ in $\mathrm{scCO}_{2}$ at 8.4 $\mathrm{MPa}$ and $312 \mathrm{~K}$ (red). Absorption and fluorescence of DCN2 in MeOH/ $\mathrm{CO}_{2}$ for $[\mathrm{MeOH}] / \mathrm{M}=3$ (blue), 14 (black), and pure methanol (green). $\mathrm{MeOH} / \mathrm{CO}_{2}$ mixtures at $307 \mathrm{~K}$ and $12 \mathrm{MPa}$ (full lines) or $25 \mathrm{MPa}$ (dashed lines); $\mathrm{MeOH}$ : $298 \mathrm{~K}$ under a $12 \mathrm{MPa}$ pressure of $\mathrm{CO}_{2}$.

large shifts, when combined with a low $\beta$. The value of $\beta$ of $\mathrm{scCO}_{2}$ remains controversial. Hyatt compared it to that of an ether, ${ }^{10 \mathrm{~b}}$ but Maiwald and Schneider reported $\beta=0 .{ }^{10 c}$ Only $\beta \approx 0$ can reconcile the shift of $\mathrm{DCN} 2$ in $\mathrm{scCO}_{2}$ with the values for $5 \mathrm{CN} 2$. The modest hypsochromic shift of the $\mathrm{R}^{*} \mathrm{O}^{-}$emission suggests that DCN2 is only ca. $1 \mathrm{p} K_{\mathrm{a}}$ unit less acidic in $\mathrm{MeOH} / \mathrm{CO}_{2}$ mixtures than in pure methanol. Protolytic photodissociation of highly acidic DCN2 in methanol-poor mixtures suggests the existence of $\mathrm{MeOH}$ aggregates and preferential solvation of DCN2 by such aggregates. Evidence for $\mathrm{MeOH}$ aggregates was also found in organic liquid and $\mathrm{sc}$ solvents. ${ }^{11}$ The full extent of the H-bonded aggregates is already observed at very low methanol concentrations.

The ratio of $\mathrm{R}^{*} \mathrm{O}^{-}$and $\mathrm{R} * \mathrm{OH}$ fluorescence intensities, $I_{\mathrm{A}} / I_{\mathrm{N}}$ in Figure 2, which is directly proportional to the ESPT rate constant, ${ }^{1 \mathrm{~b}}$ decreases with decreasing $X_{\mathrm{MeOH}}$. The lower $X_{\mathrm{MeOH}}$ values seem to extrapolate linearly to 0 and reveal that very small methanol mole fractions are needed for proton transfer to methanol. This supports the preferential solvation of DCN2 by a cluster of methanol molecules. The extrapolation to pure methanol at high pressures leads to a lower ratio than that reported by Huppert et al. for DCN2 in propanol at higher pressures. ${ }^{12 a} \mathrm{We}$ assign this to the presence of oxygen in our system. The scatter in Figure 2 reflects the reproducibility of independent measurements. This scatter is much lower within single experimental runs. The results discussed below focus on comparisons within experimental runs.

The $I_{\mathrm{A}} / I_{\mathrm{N}}$ ratios remain virtually unchanged when the temperature changes from 307 to $330 \mathrm{~K}$. Thus, temperature effects play only a minor role in our systems. ${ }^{7}$ This is expected in view of the insensitivity of the deprotonation rate of DCN2 in methanol to temperatures above the diffusion limit. ${ }^{12 \mathrm{~b}}$ However, Figure 3 shows 


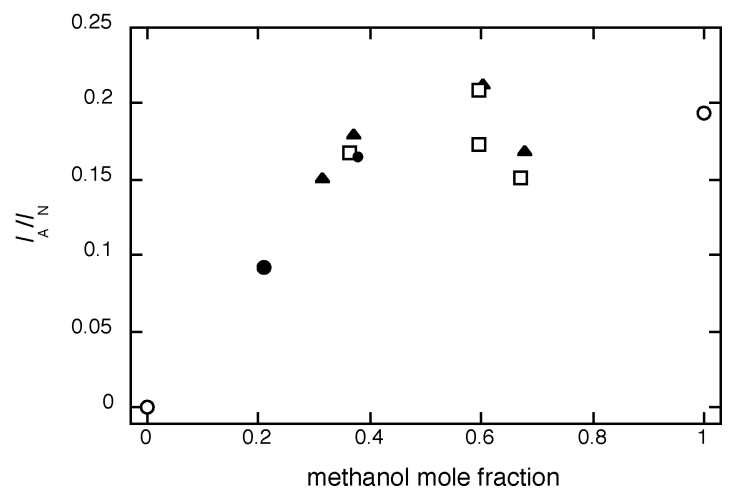

Figure 2. Ratio of $\mathrm{R}^{*} \mathrm{O}^{-}$and $\mathrm{R} * \mathrm{OH}$ fluorescence intensities as a function of $\mathrm{MeOH}$ mole fraction. Measured at $T=323 \mathrm{~K}$ and $P / \mathrm{MPa}=12$ (circles), 17.5 (triangles), and 22 (squares).

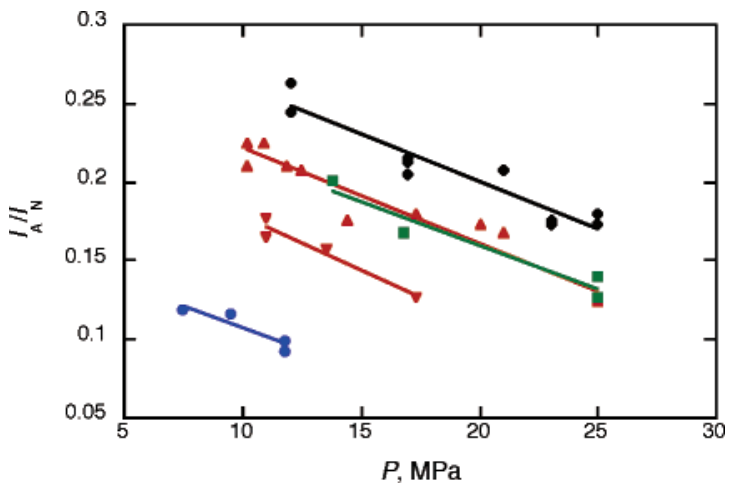

Figure 3. Ratio of $\mathrm{R}^{*} \mathrm{O}^{-}$and $\mathrm{R} * \mathrm{OH}$ fluorescence intensities as a function of pressure. Measured between 307 and $330 \mathrm{~K}$ and $[\mathrm{MeOH}] / \mathrm{M}=4$ (circles), 8 (triangles), 12 (squares), and 14 (lozenges).

that an increase in pressure leads to a very pronounced decrease in the $I_{\mathrm{A}} / I_{\mathrm{N}}$ ratio. The increase in pressure is also a dilution of methanol. For example, in the experimental run with the largest amount of $\mathrm{MeOH}$, the increase in pressure from 12 to $25 \mathrm{MPa}$ at $307 \mathrm{~K}$ corresponds to a decrease in mole fraction from 0.64 to 0.60 . Figure 2 indicates that such a decrease should lead to not more than a $10 \%$ decrease in the $I_{\mathrm{A}} / I_{\mathrm{N}}$ ratio, but a $26 \%$ decrease is observed. Furthermore, the fluorescence intensity of $\mathrm{R} * \mathrm{OH}$ almost doubles with this increase in pressure, whereas that of $\mathrm{R}^{*} \mathrm{O}^{-}$ increases very little. Thus, the $I_{\mathrm{A}} / I_{\mathrm{N}}$ ratio decreases with an increase in pressure mostly because $I_{\mathrm{N}}$ increases with pressure.

We measured the lifetimes of $\mathrm{R}^{*} \mathrm{OH}$ and $\mathrm{R}^{*} \mathrm{O}^{-}$both at 11 and $25 \mathrm{MPa}$, for $T=307 \mathrm{~K}$ and $[\mathrm{MeOH}]=14 \mathrm{M}$. The decays observed at $440 \mathrm{~nm}$ for $\mathrm{R} * \mathrm{OH}$ were nonexponential, ${ }^{7}$ with the characteristic tail observed in methanol and assigned to reversible proton geminate recombination. ${ }^{13}$ The full kinetic analysis of these decays requires information on diffusion coefficients and dielectric constants of $\mathrm{MeOH} / \mathrm{CO}_{2}$ mixtures, not readily available. However, from a multiexponential fit of the decays, we estimate average lifetimes of $1.3 \mathrm{~ns}$ at $11.5 \mathrm{MPa}$ and $2.8 \mathrm{~ns}$ at $25 \mathrm{MPa}$ ( $\chi$-squares of 1.03 and 1.10 , respectively). In $\mathrm{MeOD} / \mathrm{CO}_{2}$ mixtures these average lifetimes increase to 2.3 and $3.1 \mathrm{~ns}$, respectively. The increase of these lifetimes with pressure is consistent with the concomitant decrease in the $I_{\mathrm{A}} / I_{\mathrm{N}}$ ratio. They approach the lifetimes measured in racemic 2-butanol, where a similar $I_{\mathrm{A}} / I_{\mathrm{N}}$ ratio was also observed. The kinetic isotope effects (KIE) are low, KIE $<2$, as expected from the nearly temperature-independent $I_{\mathrm{A}} / I_{\mathrm{N}}$ ratio. The R* $\mathrm{O}^{-}$emission at $570 \mathrm{~nm}$ reveals rise times and monoexponential decays; the latter have lifetimes of $2.0 \mathrm{~ns}$ at $11 \mathrm{MPa}$ and $3.0 \mathrm{~ns}$ at $25 \mathrm{MPa}(\chi$-squares of 1.20 and 1.37). In $\mathrm{MeOD} / \mathrm{CO}_{2}$ mixtures these lifetimes increase to 3.3 and $3.6 \mathrm{~ns}$, respectively, again indicating low KIE. Thus, proton- transfer dynamics in $\mathrm{MeOH} / \mathrm{CO}_{2}$ are characterized by low kinetic barriers, but these tend to increase with pressure.

The effect of pressure on the deprotonation rate of DCN2 in ethanol and propanol has been studied by Huppert and coworkers. ${ }^{12 \mathrm{a}, \mathrm{c}}$ They find that, at low pressures, the $\mathrm{R}^{*} \mathrm{OH}$ lifetime decreases with pressure but that at higher pressures the opposite is observed. Their "low pressures" extend to $700 \mathrm{MPa}$ and include the whole range of our pressures. These authors also observe an increase in $\mathrm{R} * \mathrm{OH}$ fluorescence intensity with pressure. We assign the decrease in the $I_{\mathrm{A}} / I_{\mathrm{N}}$ ratio with pressure to an increase in the $\mathrm{R}^{*} \mathrm{OH}$ fluorescence intensity, due to less efficient proton transfer at higher pressures. Huppert and co-workers suggest the opposite, arguing for efficient proton tunneling at higher pressures. Our differences can be explained by the high compressibility of $\mathrm{MeOH} /$ $\mathrm{CO}_{2}$ mixtures, where pressure will disrupt the methanol clusters rather than bring methanol and DCN2 molecules closer together to promote tunneling. Johnston and Fox found little, if any, deprotonation of 2-naphthol in $\mathrm{scH}_{2} \mathrm{O}$ and assigned this to the loss of local water structure at elevated temperatures and pressures. ${ }^{14}$ The loss of local structure may justify the effect of pressure in the $I_{\mathrm{A}} / I_{\mathrm{N}}$ ratio and in the $\mathrm{R} * \mathrm{OH}$ lifetime observed in this study. A more complete kinetic analysis is in progress, aiming at a full characterization of the reaction dynamics in this fluid.

Acknowledgment. We thank FCT (Portugal) and FEDER (POCTI/QUI/47267/2002), and the National Science Foundation (CHE-0096941) for financial support.

Supporting Information Available: Experimental procedures, temperature and additional pressure dependences of $I_{\mathrm{A}} / I_{\mathrm{N}}$, and singlephoton counting decays of $\mathrm{R}^{*} \mathrm{OH}$ and $\mathrm{R}^{*} \mathrm{O}^{-}$. This material is available free of charge via the Internet at http://pubs.acs.org.

\section{References}

(1) (a) Förster, T. Z. Elektrochem. 1950, 54, 42-46. (b) Weller, A. Prog. React. Kinet. 1961, 1, 189-214.

(2) Arnaut, L. G.; Formosinho, S. J. J. Photochem. Photobiol. A: Chem. 1993, $75,1-20$.

(3) Tolbert, L. M.; Solntsev, K. M. Acc. Chem. Res. 2002, 35, 19-27.

(4) Tolbert, L. M.; Haubrich, J. E. J. Am. Chem. Soc. 1994, 116, 1059310600 .

(5) (a) Tomasko, D. L.; Knutson, B. L.; Eckert, C. A.; Haubrich, J. E.; Tolbert, L. M. Am. Chem. Soc. Symp. Ser. 1992, 488, 84-91. (b) Tomasko, D. L.; Knutson, B. L.; Pouillot, F.; Liotta, C. L.; Eckert, C. A. J. Phys. Chem. 1993, 97, 11823-11834

(6) (a) Chattopadhyay, N.; Serpa, C.; Silva, M. I.; Arnaut, L. G.; Formosinho, S. J. Chem. Phys. Lett. 2001, 347, 361-365. (b) Seixas de Melo, J.; Fernandes, P. F. J. Mol. Struct. 2001, 565-566, 69-78.

(7) See Supporting Information.

(8) Galicia-Luna, L. A.; Richon, D.; Renon, H. J. Chem. Eng. Data 1994 $39,424-431$

(9) (a) Solntsev, K. M.; Huppert, D.; Tolbert, L. M.; Agmon, N. J. Am. Chem Soc. 1998, 120, 7981-7982. (b) Solntsev, K. M.; Huppert, D.; Agmon, N. J. Phys. Chem. A 1998, 102, 9599-9606.

(10) (a) Marcus, Y. J. Phys. Org. Chem. 2005, 18, 373-384. (b) Hyatt, J. A. J. Org. Chem. 1984, 49, 5097-5101. (c) Maiwald, M.; Schneider, G. M Ber. Bunsen-Ges. Phys. Chem. 1998, 102, 960-964.

(11) (a) Symons, M. C. R.; Thomas, V. K. J. Chem. Soc., Faraday Trans. 1981, 77, 1883-1890. (b) Fulton, J. L.; Yee, G. G.; Smith, R. D. J. Am Chem. Soc. 1991, 113, 8327-8334. (c) Chatzis, G.; Samios, J. Chem Phys. Lett. 2003, 374, 187-193. (d) Taylor, C. M. V.; Bai, S.; Mayne, C. L.; Grant, D. M. J. Phys. Chem. B 1997, 101, 5652-5658.

(12) (a) Genosar, L.; Leidermn, P.; Koifman, N.; Huppert, D. J. Phys. Chem A 2004, 198, 309-319. (b) Cohen, B.; Huppert, D. J. Phys. Chem. 2000, 104, 2663-2667. (c) Koifman, N.; Cohen, B.; Huppert, D. J. Phys. Chem. A 2002, 106, 4336-4344.

(13) (a) Carmeli, I.; Huppert, D.; Tolbert, L. M.; Haubrich, J. E. Chem. Phys. Lett. 1996, 260, 109-114. (b) Solntsev, K. M.; Huppert, D.; Agmon, N.; Tolbert, L. M. J. Phys. Chem A 2000, 104, 4658-4669.

(14) Green, S.; Xiang, T.; Johnston, K. P.; Fox, M. A. J. Phys. Chem. 1995, 99, 13787-13795

JA052416O 